\section{DISINFECTANT WIPES SPUN FROM LACE}

Septalkan soft Spun-Lace Wipes are alcohol free, dye free, allergen free and fragrance free. They are saturated in solution and scientifically developed for medical devices.

Septalkan Wipes from Alkapharm are bactericidal, yeasticidal and virucidal, and designed for

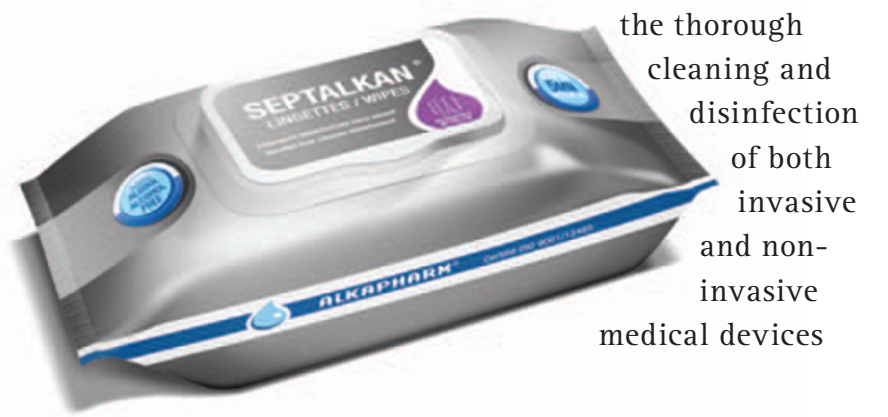

\section{COMPOSITE LAYERING COMPETITION WINNERS}

The DENTSPLY Ceram X Case Contest is aimed at dental students wishing to practise composite layering techniques with Ceram.X nano-ceramic single and dual layer composite. The students supply clinical poster cases to the DENTSPLY judging panel for the chance to win prizes.

The winner of the Ceram X Case Contest 2013 is Rebecca Morgan from UCLan, whose case was a first class example of how modern resin composite materials can be used to restore worn dentitions in an efficient and relatively economic fashion with dramatic aesthetic and functional improvement. Rebecca's case also achieved fifth place in the World Final.

Second place is Julia Bernardo from Peninsula College of Medicine and Dentistry. The judges felt and equipment. High level active disinfection is triggered from contact to $99.9999 \%$ activity. Septalkan Wipes are intended for single use so rinsing is not required.

Septalkan Spun-Lace Wipes are now available in soft flow dispense packs each containing 100 Spun-Lace Wipes $(200 \times 180 \mathrm{~mm})$.

For comprehensive product information ask your dealer representative and/or visit www. alkhapharm.co.uk. that the build-up of the lateral incisors and the reduction of anterior spacing in Julia's case was carried out with a high level of skill. The final aesthetic outcome was impressive with excellent contouring, colour matching and polishing.

Third place is Brendan Quinn from University College Cork and honorary mention goes to Hassan Adi from Birmingham Dental School.

DENTSPLY extends its congratulations to the winners.

\title{
EASIER MANIPULATION AROUND GUMS
}

The Gumsaver is a long-handled interspace brush that gives the patient better access and easier manipulation. Invented by a UK dentist, Gumsaver's unique design enables the patient to effectively clean the sub-gingival biofilm at home, significantly reducing inflammatory markers in between visits to the hygienist. The soft, pointed bristles can be used on the most sensitive gums, reaching down into the periodontal pockets to remove bacteria. It is the ideal applicator for chlorhexidine gels/mouthwash, ensuring the medicine is targeted to the right area and so accelerating healing for the patient. Gumsaver is the easiest management technique for gingivitis and periodontitis, helping you to increase patient compliance and reduce treatment time in clinic.

With its tapered bristles and long handle, Gumsaver gives the user access all areas - making the job of cleaning around braces, bridgework, crowns, implants and all those awkward to reach areas efficient and less time consuming, for fantastic results that last.

Try it today: recommend the Gumsaver to your patients. Call 08450944233 or visit www.gumsaver. co.uk for further information.

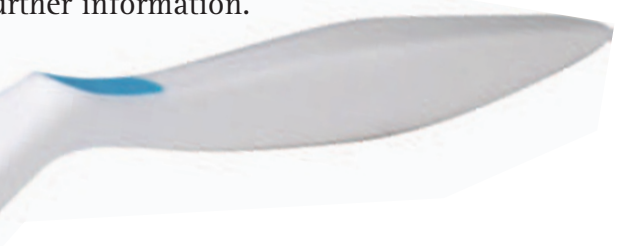

\section{FREE ORAL HYGIENE DISPLAY STAND}

Plandent is introducing the Edel and White range of oral hygiene products exclusively through dental practices in UK and Ireland. As an introductory offer, you will receive a free product display dispenser stand for your practice when you order your first $£ 100$ of Edel and White products.

The oral hygiene range includes the hydro active Sonic Generation toothbrush, creating a pulsating flow that neutralises bacteria far beyond the reach of the bristles, providing gentle plaque removal and preventing its development. Up to 45,000 sonic active movements per minute accelerate dental care and enhance cleaning efficiency by more than 30\%. The new Dual Clean brush head with micro-fine bristles channel the energy waves straight into little niches at the same time preserving the soft tissue due to its brush-like cut. The result is a highly efficient and gentle deep cleansing for naturally white and healthy teeth. The Sonic Generation is even suitable for sensitive teeth.

For those preferring a manual brush, the dual cleaning action of Edel and White's manual toothbrushes are perfect. The tapered bristles remove plaque from the teeth, even at the borderline of the gums, more effectively than ordinary toothbrush bristles.

The full range of products includes adult and children's toothpaste, interdental brushes, floss and tongue cleaners, enabling your practice to generate extra income.

For further information or to request your free full-colour comprehensive catalogue contact Plandent on Freecall 0500500322. 